\title{
ANALISIS STRATEGI E-PROMOTION JASA MAKE-UP ARTIST MELALUI INSTGRAM (Studi Pada Chels Makeup artist di Bandar Lampung)
}

\author{
Damayanti $^{1}$ ) Suprihatin Ali ${ }^{2}$ ) Mediya Destaia ${ }^{3}$ ) \\ 1) Ilmu Administrasi Bisnis, Universitas Lampung, email: damayanti.1981@ fisip.unila.ac.id \\ 2) Ilmu Administrasi Bisnis, Universitas Lampung, email: suprihatin.ali@fisip.unila.ac.id \\ 3) Ilmu Administrasi Bisnis, Universitas Lampung, email: mediya.destalia@ fisip.unila.ac.id
}

\begin{abstract}
This study aims to analyze the e-promotion strategy carried out by chels.makeupartist through instragam. . The research method that used is qualitative research with content analysis approach model and the main data source in this study is Instagram. The findings in this study are the promotional strategies conducted by chels.makeupartist are social media strategies, especially Instagram. In this social media strategy it contains advertising, publicity and sales promotions for either the services or goods offered. The promotion is done by displaying the portfolio of services that have been done on the Instagram account they have.
\end{abstract}

Keywords: e-promotion, make up artist, Instagram, e-marketing

\begin{abstract}
Abstrak
Penelitian ini bertujuan untuk menganalisis strategi e-promotion yang dilakukan oleh chels.makeupartist melalui instragam. . Metode penelitian yang digunakan adalah penelitian kualitatif dengan pendekatan pendekatan analisis isi dan sumber data utama dalam penelitian ini adalah Instagram. Temuan dalam penelitian ini adalah strategi promosi yang dilakukan oleh chels.makeupartist adalah strategi media sosial, khususnya Instagram. Dalam strategi media sosial ini berisi iklan, publisitas dan promosi penjualan baik untuk layanan atau barang yang ditawarkan. Promosi dilakukan dengan menampilkan portofolio layanan yang telah dilakukan pada akun Instagram yang mereka miliki.
\end{abstract}

Kata Kunci: e-promotion, make up artist, Instagram, e-marketing 


\section{PENDAHULUAN}

Pesatnya teknologi informasi mempengaruhi proses pemasaran suatu bisnis yang awalnya face to face menjadi screen to face yang dinamakan dengan internet marekting (e-marketing). Internet memberikan peluang bisnis untuk terkoneksi dengan jaringan internet global dalam rangka memasarkan produk atau jasa yang mereka miliki dengan lebih cepat dan konsumenpun dapat melihat produk dan jasanya secara langsung tanpa harus menunggu lama.

Pengguna internet, khususnya media sosial semakin bertambah tiap harinya yang didukung dengan provider telepon seluler yang semakin inovatif, sehingga yang awalnya sistem pemasaran dilakukan dengan cara konvensional melalui pamflet, brosur, majalah dan koran mulai berganti

secara online. Kecenderungan ini disebabkan oleh informasi mengenai barang dan jasa yang dibutuhkan dapat diperoleh dengan mudah melalui fasilitas internet. Selain itu, konsumen dapat menghemat waktu dan lebih praktis dalam melakukan pembelian disebbakan oleh rutinitas yang pada di era digital ini.

Menurut Wikstrom dan Wigno dalam Moriansyah, La (2015), penggunaan media sosial sebagai suatu alat komunikasi pemasaran tidak hanya menggunakan internet dan teknologi, akan tetapi harus menggunakan suatu strategi komunikasi yang tepat sasaran. Komunikasi pemasaran merupakan proses penyebaran informasi mengenai perusahaan dan produk yang

ditawarkan kepada pasar sasaran. Komunikasi pemasaran terintegrasi dalam dialog antara penjual dan pembeli yang sifatnya lebih personalized, customeroriented dan technology-driven. (Tjiptono dan Chandra, 2017).

Pengguna instragram mengalami peningkatan dari awal kemunculannya, yakni dari tahun 2010 hingga tahun 2017. Didorong oleh fitur Stories, sign up via Web dan fitur pembaruan lainnya., tingkat pertumbuhan Instagram semakin cepat. Butuh waktu hanya empat bulan untuk menambahkan 100 juta pengguna sejak mencapai 600 juta di bulan Desember 2016 ke April 2017. Sementara itu, butuh waktu enam bulan untuk pergi dari 500 juta menjadi 600 juta dari 21 Juni 2016 sampai dengan 15 Desember 2016 (http://

indonesiago.digital, 2017). Peningkatan pengguna aktif instagram ini membuat pegiat bisnis mulai memasarkan produk dan jasanya ke media sosial Instagram karena dapat secara langsung mengunggah visual produk atau jasa yang akan mereka

pasarkan. Berpindahnya pemasaran ke media sosial yang satu ini memunculkan adanya fenomena baru dalam strategi komunikasi pemasaran melalui internet dalam hal ini media sosial.

Bisnis jasa make-up artist berkembang dengan pesat seiring perkembangan rutinitas manusia, sehingga bisnis ini banyak digeluti oleh pelaku bisnis. (www.tribunnews.com, 2015). Sebelumnya hanya dilakukan secara konvensional yakni melalui mouth to mouth, iklan baik pada media cetak dan radio, akan tetapi saat ini bisnis ini mulai memanfaatkan instagram untuk memasarkan jasa make-upnya kepada konsumen. Instagram dianggap sebagai salah satu media komunikasi pemasaran baru yang efektif yang dianggap mampu untuk menjembatani komunikasi pemasaran bagi pemiliki bisnis kepada konsumen. Menurut Kotler (2010), pemasaran melalui media online diminati karena memiliki beberpa manfaat bagi konsumennya. Pembelian secara online ini nyaman, pelanggan tidak perlu bergelut dengan lalu lintas, mencari tempat parkir, dan berjalan dari toko ke toko dan konsumen dapat memesan barang selama 24 jam sehari dari mana dan kapan saja. Selain itu masih menurut Kotler, pembelian online itu berisifat interaktif dan segera, yakni pembeli dapat berinteraksi dengan situs penjual untuk mencari informasi dan kemudian melakukan pemesanan di tempat.Hal ini menunjukkan bahwa saat ini 
Damayanti, Suprihatin \& Mediya, analisis strategi e-promotion jasa make-up artist melalui instgram....

beberapa orang nyaman berbelanja secara online dikarenakan dapat diakses dengan mudah dan tidak merepotkan.(Lestari, 2015).

Penelitian ini memfokuskan pada jasa make-up, karena perkembangan bisnis ini sangat pesat, ditandai dengan semakin banyaknya pelaku bisnis make-up tiap tahunnya. Berdasarkan hal tersebut peneliti yang menjadi pertanyaan dalam penelitian ini adalah adalah bagaimana strategi promosi yang dilakukan oleh Chels MakeUp Artist melalui instagram? Berdasarkan pertanyaan ini, peneliti kemudian melakukan analisis strategi promosi yang dilakukan oleh Chels makeup artist dalam komponen postingan dalam instagram yang mendorong interaksi antara pengguna dan pengikut akun tersebut. Komponen yang dicermati berupa jenis foto/gambar dan video yang diposting dalam akun tersebut.

\section{METODE}

Penelitian ini menggunakan jenis penelitian kualitatif dengan model pendekatan content analysis. Instagram merupakan sumber data utama untuk menganalisis penelitian ini. Akun yang menjadi objek dalam penelitian ini adalah akun media sosial instagram chels. makeupartist, yang menyedikan jasa makeup artist di kawasan Lampung.

Populasi dalam penelitian ini berupa foto yang diupload oleh akun
Chels.makeupartist sebanyak 3.862 foto yang telah di posting dari 24 Desember 2014 sampai dengan 5 Agustus 2018 dengan jumlah followers 19.900 orang. Selain melakukan pengamatan pada foto yang diposting, peneliti juga melakukan wawancara kepada pemilik Chels.makeupartist untuk menggali lebih dalam mengenai tujuan strategi promosi dalam foto/gambar yang diposting.

\section{HASIL DAN PEMBAHASAN}

Profil Akun Chels.makeupartist

Chels.makeupartist didirikan oleh Amanda Malphi, berusia 27 tahun, yang bertempat di Jalan Malabar Wayhalim Permai. Usaha jasa ini didirikan tahun akhir 2014 dengan modal awal sebesar Rp.500.000 dengan tarif yang dikenakan untuk setiap jasa yang dikeluarkan sebesar Rp.50.000. Amanda memulai promosikan jasa make-upnya melalui Instagram (IG) pada tanggal 24 Desember 2014 dengan nama akun "chels.makeupartist" seperti yang terlihat pada Gambar 1. Alasan menggunakan IG dalam mempromosikan jasanya, yaitu karena dapat bertemu dan berinteraksi secara langsung dengan konsumen dengan cara memposting foto dan video kegiatankegiatan yang telah dilakukan dan abarang yang siap untuk dijual. Tim make-uap artistnya terdiri dari 12 orang yang diseleksi dari siswa terbaik dari kelas kursus privat yang ditawarkan.

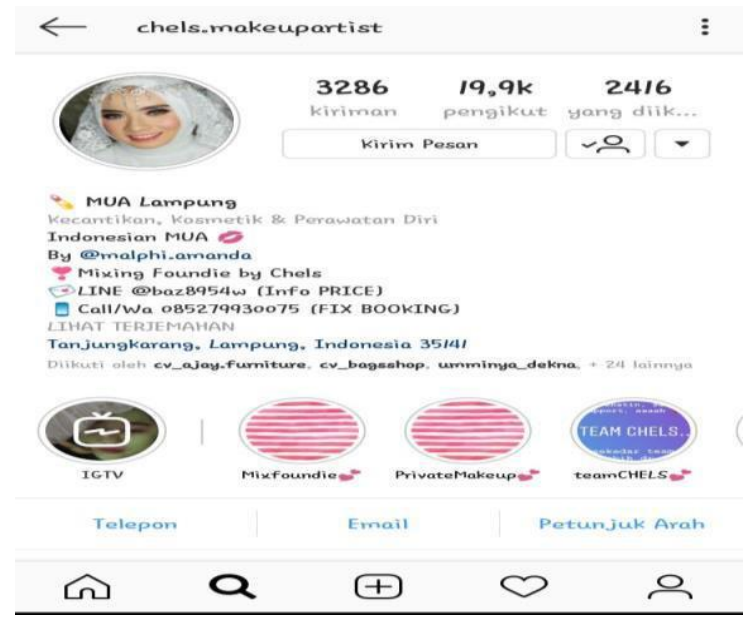

Gambar 1. Profil Akun Chels Make-Up Artist di Instagram 
Berdasarkan gambar 1. dapat diketahui bahwa pengikut akun chels.makeupartist sebanyak 19.900 orang, nomor kontak person yang bisa dihubungi melalui media whatsapp (WA) khusus untuk pemesanan atau booking dan LINE untuk pertanyaan tentang tarif jasa, akun pemilik usaha dan alamat chels.makeupartist secara offline.

Pada awalnya jasa make-up yang ditawarkan hanya berupa make-up pesta, wisuda karena sasaran konsumennya hanya teman terdekat saja, tetapi untuk saat ini jasa/barang yang ditawarkan lebih beragam, antara lain:

1. Make-up pesta/wisuda/perpisahan dengan tarif Rp.230.000.

2. Make-up pra-wedding dengan tarif Rp.400.000 hanya untuk jasa makeupnya saja, Rp.1.500.000 untuk jasa make-up dan fotografinya.

3. Make-upweddingdengantarif

Rp.4.000.000 untuk di Bandar Lampung dan ditambah Rp.1.500.000 untuk wilayah di luar Bandar Lampung.

4. Make-up lamaran dengan tarif Rp.350.000.

5. Jasa Private Course sebesar Rp.1.000.000 per satu kali pertemuan.

6. Jasa Beauty Class dengan tarif Rp.300.000 di mana beauty class ini bekerja sama dengan pihak luar, seperti Elf.Organizer (perusahaan yang bergerak dibidang even organizer) dan produk kosmetik tertentu.

7. Untuk barang, chels.makeupartist juga menjual produk kosmetik dan mix foundation yang dibuat sendiri oleh pemilik usaha ini. Mix foaundation dijual dengan harga Rp.350.000 untuk toples besar dan Rp.200.000 untuk toples.

\section{Startegi Promosi Chels.makeupartist}

Strategi promosi yang dilakukan chels.makeupartist adalah startegi media sosial, yaitu media sosial yang dimiliki didesain untuk berinteraksi dengan konsumennya yang bersifat dua arah dan interaktif. Media Sosial merupakan sebuah media online yang penggunanya bisa dengan mudah berpartisipasi, berbagi, dan menciptakan isi meliputi blog, sosial network atau jejaring sosial, wiki, forum dan dunia virtual (Hidayatullah, 2016). Media sosial ini mengubah pola penyebaran informasi melalui teknologi internet yang bersifat social media monologue (dari banyak audiens ke banyak audiens). Dalam berinteraksi dengan konsumen/pengikutnya, chels.makeupaartist menggunakan media sorotan/highight, instastory dan postingan foto/video.

Strategi media sosial chels.makeupartist mengandung (1) iklan (advertising), yang berupa informasi atau pesan yang disampaikan kepada pengikutnya dengan tujuan untuk memperkenalkan, mengajak dan membujuk pengikutnya untuk menggunakan jasa MUA yang ditawarkan,

(2) publisitas yang mendorong untuk mempengaruhi konsumen dalam startegi membangun citra, strategi branding dan memperluas pemasarannya, (3) promosi penjualan. Promosi penjualan memilki aktivitas berupa pameran dagang, kontes, sampel, insentif perdagangan dan kupon

(Simamora, 2007). Dalam hal ini, chels.makeupartis melakukan promosi penjualan berupa postingan portofolio hasil jasa makeup artist, promosi give away, promosi prewedding, pomosi kegiatan yang bekerja sama dengan salah satu brand produk kecntikan dan even organizer, dll. Melalui instagram, chels.makeupartist menyediakan konsep visual yang mendorong jasanya akan dilihat oleh orang banyak dan chels.makeupartist memanfaatkan portofolionya dan keindahan konten dalam foto yang diposting yang akan membuat pengikutnya memutuskan untuk menggunakan jasanya.

Chels.makeupaartist memanfaatkan media yang ada dalam instragram, seperti sorotan, instastory dan postingan foto/video. Terdapat 38 sorotan/hihlight dalam akun chels.makeupartist yang terdiri dari promosi mengenai tersedianya mixing foundation yang siap dijual, proses beauty class, kegiatan private make up class, promosi penjualan alat make up, tim chels make up artist yang terdiri dari 12 orang, aturan 
Damayanti, Suprihatin \& Mediya, analisis strategi e-promotion jasa make-up artist melalui instgram....

booking jasa make-up dan informasi mengenai harga yang hanya bisa didapat via LINE, portofolio hasil jasa make-up, alamat chels make-up, tutorial make-up, kegiatan workshop tentang make up yang diikuti oleh tim chels make up artist. Contoh sorotan/highlight dalam akun chels dapat dilihat pada Gambar.2. Untuk instastory yang dilakukan oleh akun chels.makeupartist biasanya berupa testimony customer, kegiatan endors barang, demo make up yang biasanya berupa siaran langsung, sehingga dapat direpon langsung oleh pengikut akun. Respon yang dilakukan pengikut berupa pertanyaan penggunaan alat make up, pertanyaan produk yang dipakai oleh chels.makeupartis dan pujian terhadap demo makeup tersebut.

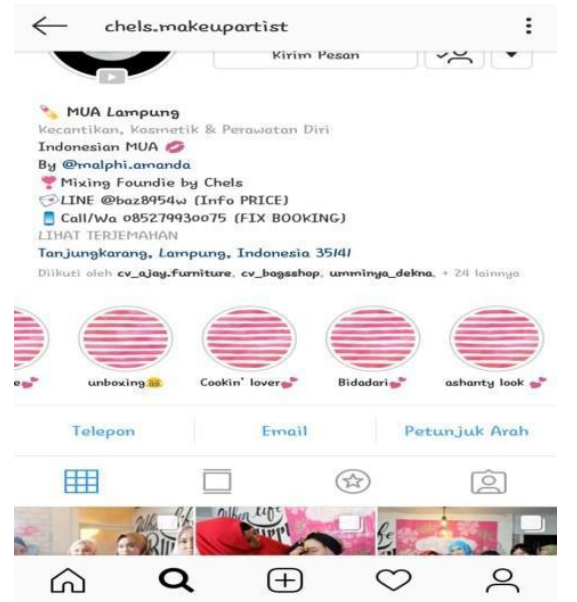

Gambar 2. Sorotan/Higlight dalam akun Chels.Makeup artist

Dalam hal postingan, foto/gambar yang diposting oleh chels.makeupartis sebanyak 3.286 postingan dari 24 Desember 2014 sampai dengan 5 Agustus 2018.. Dari total postingan terdapat 3.228 postingan mengenai kegiatan chels.makeupartist, sedangkan sisanya 58 postingan tentang kegiatan endors yang dilakukan pemilik - chels.makeupartis. 3.228 postingan tersebut yang terdiri dari:

1. Pelaksanaan kegiatan beauty class $(9$ postingan). Postingan pelaksanaan kegiatannya dapat dilihat pada Gambar 3.

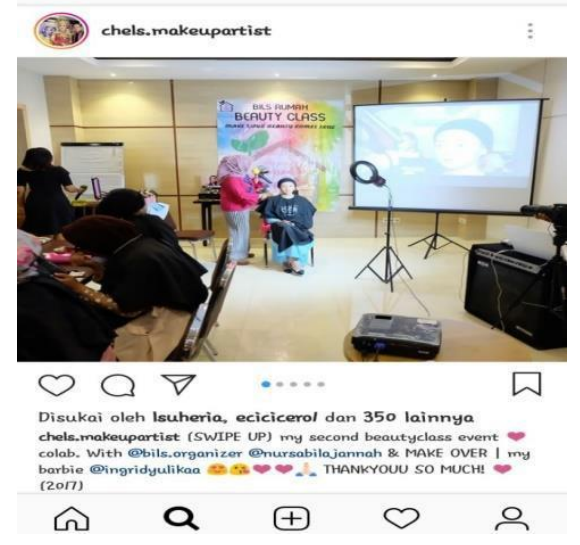

Gambar 3. Postingan Pelaksanaan Kegiatan Beauty Class di akun Chels.makeupartist 
2. Demo makeup (3 postingan). Demo make up ini bekerjasama dengansalah satu brand produk kecantikan,yaitu ultima II dan even organizer yang bernama akun instagram bils.organizer, seperti yang terlihat pada Gambar 4.

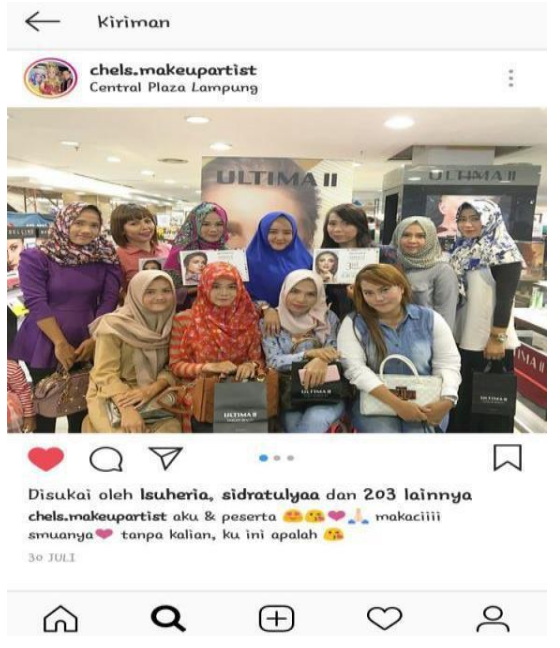

Gambar 4. Postingan Demo Makeup di akun Chels.makeupartist

3. Testimoni customer (123 postingan). Tujuan ditampilkannya testimoni dalam postingan di akun ini, agar konsumen dalam hal ini pengikut akun mengetahui bahwa hasil jasa makeup yang dilakukan telah memberikan kepuasan 4. . pada akhirnya pengikut teratrik untuk menggunakan jasa makeup dari chels. Contoh testimony yang diposting oleh chels.makeupartis dapat dilihat pada Gambar

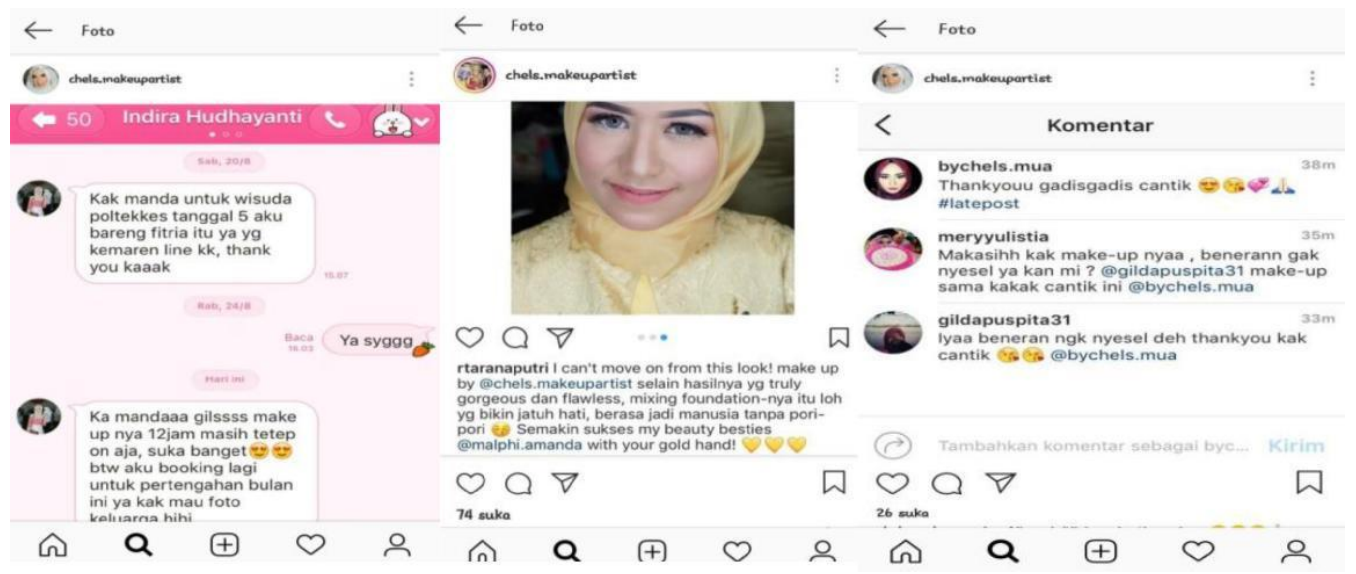

Gambar 5. Postingan Chels.makeupartist mengenai Testimony Konsumen, baik melalui

kolom komentar di postingan IG,

via LINE maupun akun pribadi konsumen. 
Damayanti, Suprihatin \& Mediya, analisis strategi e-promotion jasa make-up artist melalui instgram....

5. Portofolio hasil jasa make up (3.002 postingan). Portofolio hasil jasa make up sengaja ditampilkan dalam akun isntagram agar pengikut dapat melihat secara langsung hasil jasa makeup dari chels dan promosi dapat lebih cepat sampai ke konsumen/pengikut dan mereka bisa langsung membandingkan dengan hasil jasa makeup dengan akun jasa makeup lainnya yang memposting portofolio jasa makeup mereka.. Selain itu tujuan portofolio ini juga memberikan citra di benak konsumen bahwa hasil makeup sangat bagus dan bisa membuat konsumen lebih cantik dan percaya diri. Pada awalnya chels.makeupartist memposting foto before \& after konsumen yang telah dimake up, tetapi banayk konsumen yang memprotes hasilnya dipromosikan, maka saat ini yang ditampilkan hanya after make up-nya saja, yang dapat dilihat pada Gambar 6 .

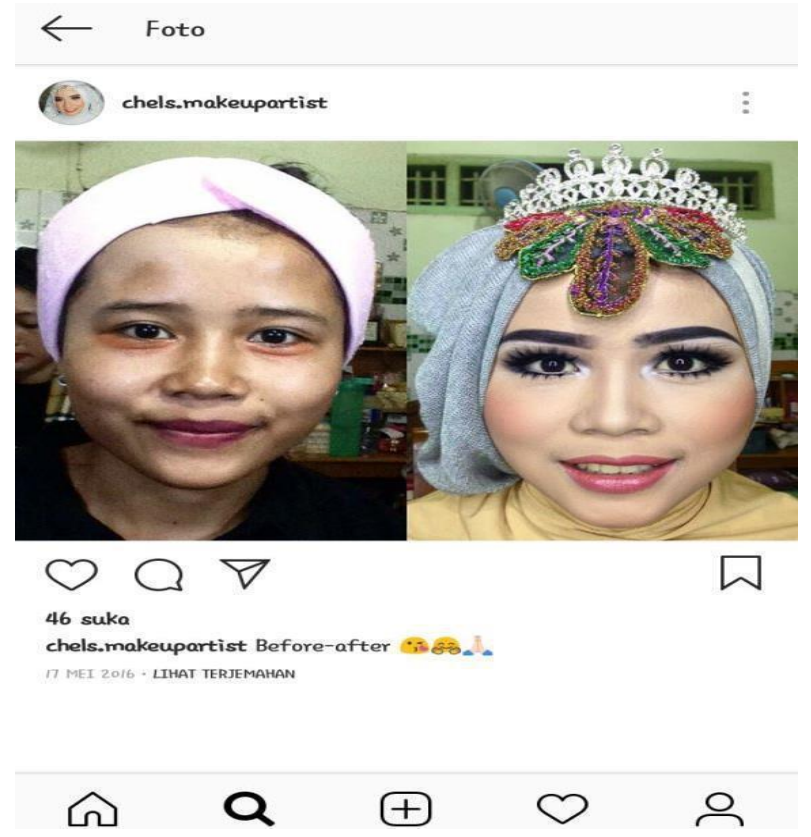

Gambar 6. Contoh Postingan Portofolio Hasil Jasa Makeup Chels.makeupartist.

6. Iklan beauty class (6 postingan). Isi dari potingan yaitu informasi mengenai pembukaan beauty class yang disertai dengan fasilitas yang akan didapat oleh peserta beauty class, waktu dan tempat, harga kursus dan sponsor yang bekerja sama dalam penyelenggaraan kegiatan ini dan contact untuk pendaftaram . Sponsor yang pernah bekerja sama antara lain, brand produk kecantikan pixy, make over, gatsby, grannys nest \{tempat penyelenggaraan), dll speerti yang terlihat dalam Gambar 7.
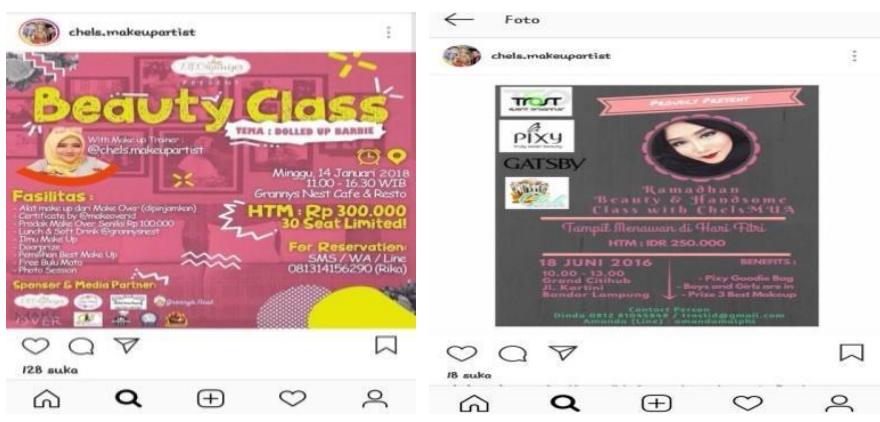

Gambar 7. Postingan Iklan Beauty Class 
7. Iklan mengenai pembukaan make up private class ( 2 postingan). Postingan iklanprivatmakeupclass menginformasikanbahwachels membuka kelas privat makeup yang ditambah dengan caption waktu dan tempat seperti pada Gambar 8.

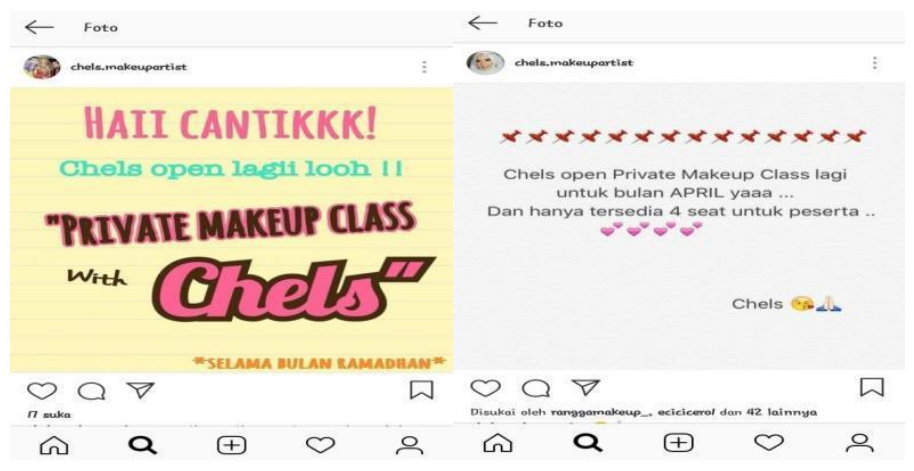

Gambar 8. Postingan Iklan Privat Makeup Class

8. Iklan pejualan mixing foundation (2 postingan).

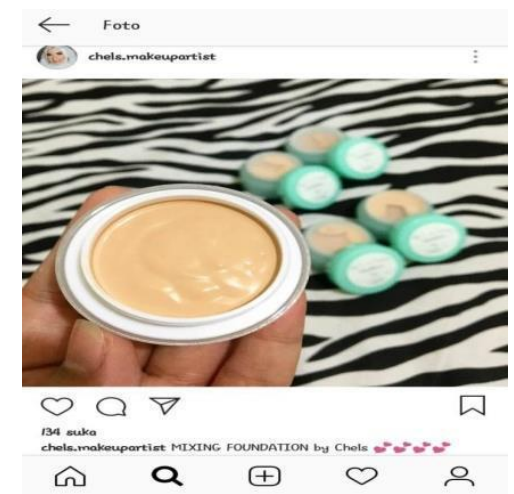

Gambar 8. Postingan Promosi Penjualan Foundation Mix

9. Promosi pre wedding (1 postingan). Promosi Pre wedding bekerja sama dengan One7photo studio yang menawarkan paket pre wedding dengan menabah informasi di dalam captionnya

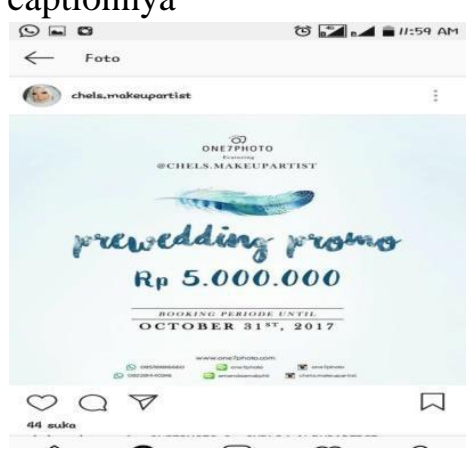

Gambar 9. Promosi Prewedding Chels.Makeupartist yang Bekerjasama mengenai apa saja fasilitas yang akan didapat dan contact person yang bisa dihubungi jika ingin menggunakan jasa ini, seperti pada Gambar 9. 
Damayanti, Suprihatin \& Mediya, analisis strategi e-promotion jasa make-up artist melalui instgram....

\section{Dengan One7photo Studio}

10. Promosi give away (1 postingan). Gambar 10 menunjukkan bahwa

foto yang diposting berupa informasi chels.makeupartis melakukan promosi berupa give away pada konsumennya mengenai hadiah dan persyaratan yang ahrus dipenuhi bagi konsumen yang dengan menambahkan caption pada ingin mengikuti promo give away.

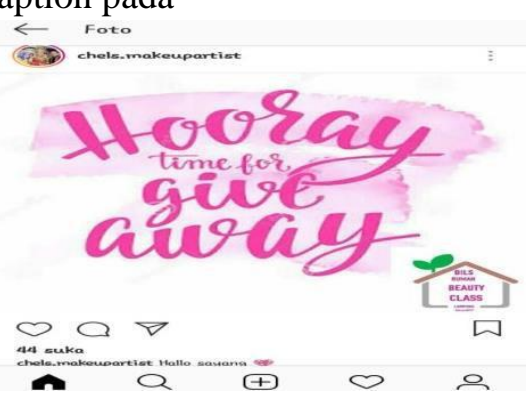

\section{Gambar 10. Postingan Promo Give Away}

11. Peralatan dan perlengkapan make up (65 postingan). Tujuan dipostingnya peralatan dan perlengkapan make up adalah agar calon konsumen mengetahui kualitas peralatan dan perlengkapan yang digunakan oleh chels.makeupartist. Pada Gambar 11.
Dapat diketahui bahwa produk makeup yang mereka gunakan adalah produk yang terkenal dan memiliki harga yang tebilang tidak murah, seperti make over, NYX, channel dan lain sebagainya.

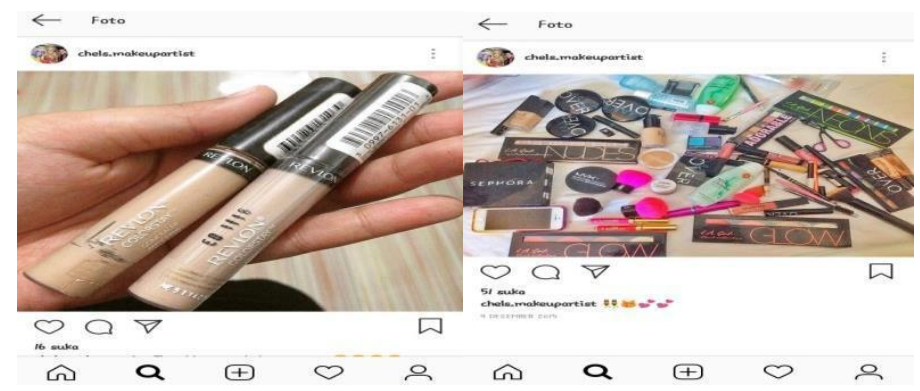

Gambar 11. Postingan Peralatan Make up yang digunakan oleh Chels.makeupartist

12. Tim chels.makeupartst (6 postingan)

13. Publikasi chels.makeupartis melalui media cetak (1 postingan).

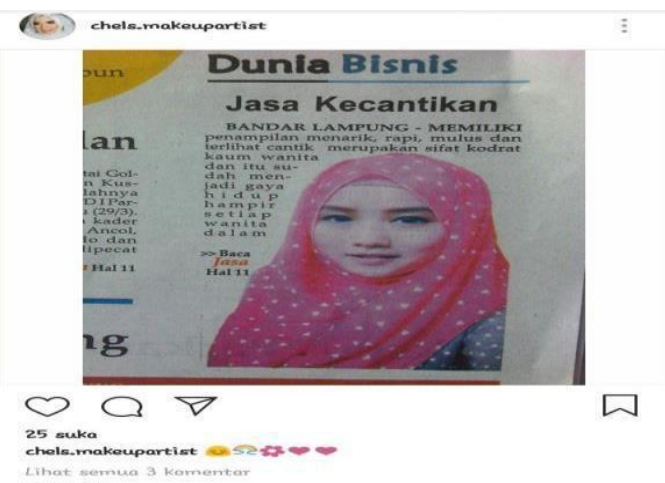

Gambar 12. Postingan Publikasi melalui Media Cetak di akun Chels.makeupartist 
14. Jadwal jasa make up yang telah dipesan olehkonsumen.(6postingan).

Postingan ini bertujuan untuk menginformasikan kepada pengikutnya bahwa pada tanggal tersebut jasa makeup telah dipesa, sehingga tidak bisa menambah konsumen lagi. Selain itu, postingan ini akan memberikan citra bahwa chelsmakeupartist memiliki pelanggan yang banyak dan jika ingin menggunakan jasanya harus pesan dari jauh hari.

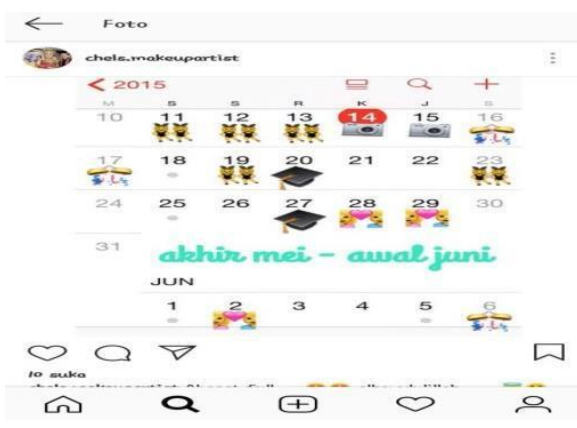

Gambar 13. Postingan Jadwal jasa make up yang telah dipesan konsumen

15. Alamat Chels.makeupartist. tujuan dipostingnya alamat chels.makeupartist

untuk menginformasikan tempat jasa makeup dan private makeup class.

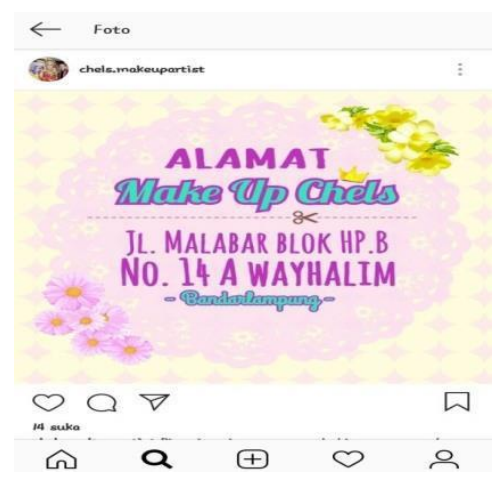

Gambar 14. Postingan Alamat Chels.makeupartist

Konsumen dalam merespon setiap postingan baik foto maupun video kegiatan jasa chels.makeupartis tidak langsung merespon dalam setiap postingan., tetapi mereka merespon melalui whatsapp, LINE atau direct messege yang ada di instagram. Respon konsumen terhadap postingan yang dilakukan chels biasanya berupa pertanyaan harga baik jasa maupun produk yang dijual sampai dengan booking jasa make up. Selain itu mereka melakukan testimony pelanggan melalui media langsung seperti WA dan LINE atau memposting hasil make up dari chels.makeupartist dalam akun pribadi konsumen yang bersangkutan seperti gambar... Hasil wawancara mengungkapkan bahwa konsumen yang pernah menggunakan jasa make up chels.makeupartist biasanya memberikan testimony dan melakukan penggunaan jasa berulang. Hal ini membuktikan bahwa

chels.makeupartist memiliki strategi promosi yang cukup efektif dalam menarik perhatian konsumen dan memberikan pelayanan jasa yang sesuai dangen keinginan konsumen. 
Damayanti, Suprihatin \& Mediya, analisis strategi e-promotion jasa make-up artist melalui instgram....

\section{KESIMPULAN}

Berdasarkan hasil penelitian, maka kesimpulan penelitian ini adalah chels.makeupartist memliki strategi promosi berupa pemanfaatan media instagram yaitu (1) melalui instastory berupa testimoni konsumen, kegiatan endors produk dan siarang langsung demo make up, (2) melalui sorotan/highligh yang terdiri dari hasil jasa make up, aturan

booking jasa make up, alamat chels.makeupartist, kegiatan beauty class dan private class make up, tutorial make up dan penjulan produk kecantikan dan mixin foundation, (3) postingan foto dan video

\section{DAFTAR PUSTAKA}

Hidayatullah, Nurul. 2016. Promosi PenjualanMelalui Jejaring Sosial (Studi Deskriptif Kualitatif Promosi Penjualan melalui Jejaring Sosial Twitter pada "Coffee House Ulee Kareng”). Jurnal Ilmu Komunikasi

Flow. Vol 2, No 18. https://jurnal.usu.ac.id/flow/article/vie w/12862

Kotler, Philips dan Keller, Kevin Lane. 2010. Manajemen Pemasaran. Erlangga. Jakarta

Moriansyah, La. 2015. Pemasaran Melalui Media Sosial: Antecedents Dan

Consequences. Jurnal Penelitian Komunikasi dan Opini Publik Vol. 19 No.3, Desember 2015: 187-196

Simamora, Henry. 2007. Manajeman Pemasaran Internasional, Jilid II, edisi 2. Penenrbit Rineka Cipta. Jakarta.

Tandusan, Chevy F.2015. Analisis Komparasi Efektivitas Penjualan Sebelum Dan Sesudah Menggunakan Video Marketing Online Talk Fusion Di Manado. Jurnal Riset Bisnis dan Manajemen Vol.3 ,No.2, 2015:141154.

Survey Pengguna Aktif Instagram, Tahun 2017.http;//indonesiago.digital (2017) yang berupa portofolio hasil jasa make up, pelaksanaan kegiatan beauty class, pelaksanaan kegiatan demo make up, testimoni customer, iklan pembukaan private class dan beauty class, promosi pembukaan beauty class, promosi penjualan mixing foundation, promosi give away, promosi ulang tahun, promosi jasa pre wedding.

Chels.makeupartist menggunakan
instagram sebagai media untuk
mempromosikan dirinya baik
bersama-sama atau secara personal.
Chels.makeupartist melakukan promosi
dengan menyiarkan portofolio dirinya
dalam akun instagram yang mereka miliki

Bisnis Jasa Penatar Rias Panggilan Makin Kinclong. www.tribunnews.com 18 Mei 2015 